\title{
HUBUNGAN FAVORITISME ORANG TUA DENGAN SIBLING RIVALRY
}

\author{
Nola Aulia Tasya \\ Mahasiswa S1 Psikologi, Fakultas Kedokteran, Universitas Lambung Mangkurat
}

Jalan Ahmad Yani KM.36, Banjarbaru, 70712, Indonesia

E-mail :2010914120023@mhs.ulm.ac.id

\begin{abstract}
Abstrak : Orang tua merupakan pondasi utama bagi anak untuk pertumbuhan dan perkembangannya. Pola asuh orang tua yang tepat akan menciptakan karakter dan kepribadian anak yang baik. Bagi orang tua yang memiliki lebih dari satu anak pasti akan menemukan bahwa mereka merasa lebih selaras dengan satu anak daripada yang lain. Orang tua akan cenderung menyukai salah seorang anak karena kepintaran maupun tampilan fisik. Sikap inilah yang sering disebut sebagai favoritisme orang tua. Kemudian akan timbul rasa tidak suka atau bersaing dengan saudara kandung. Anak yang kurang perhatian biasanya akan melakukan berbagai cara untuk mendapatkan perlakuan yang sama dari orang tuanya. Maka akan timbul sibling rivalry, yaitu pertentangan yang terjadi antar saudara kandung. Tujuan dari penulisan ini adalah untuk mengetahui hubungan favoritisme orang tua dengan sibling rivalry. Penulisan ini menggunakan metode kajian literatur dimana mengumpulkan data dengan mencari atau menggali data dari berbagai literatur seperti buku, jurnal ilmiah maupun sumber tulisan yang lain terkait dengan apa yang dimaksudkan dalam rumusan masalah. Hasil yang didapat dari penulisan ini adalah sibling rivalry terjadi karena pola asuh orang tua yang mengistimewakan salah seorang anak, perbedaan usia, jumlah saudara, jenis kelamin dan lainnya.
\end{abstract}

Kata kunci : favoritisme orang tua, sibling rivalry, persaingan

Abstract : Parents are the main foundation for children for their growth and development. The right parenting style will create a good character and personality of the child. Parents of more than one child will undoubtedly find that they feel more in tune with one child than another. Parents will tend to like a child because of intelligence and physical appearance. This attitude is often referred to as parental favoritism. Then there will be feelings of resentment or competition with siblings. Children who don't pay attention usually will do various ways to get the same treatment from their parents. Then there will be sibling rivalry, namely conflicts that occur between siblings. The purpose of this paper is to determine the relationship between parental favoritism and sibling rivalry. This writing uses the literature review method which collects data by searching or extracting data from various literatures such as books, scientific journals and other sources of writing related to what is meant in the formulation of the problem. The results obtained from this paper are that sibling rivalry occurs because of the parenting styles of parents who prefer one of the children, differences in age, number of siblings, gender and others.

Keywords : parental favoritism, sibling rivalry, competition 


\section{PENDAHULUAN}

Orang tua atau keluarga adalah tempat pertama bagi anak, karena dengan orang tua pertama kali anak memulai berinteraksi serta mendapat pengalaman-pengalaman baru di hidupnya. Pendidikan anak dalam keluarga merupakan awal dan pusat bagi seluruh pertumbuhan dan perkembangan anak untuk dewasa, dengan demikian menjadi hak dan kewajiban orang tua sebagai penanggung jawab yang utama dalam mendidik dan mengasuh anaknya. (Ansyah, Safitri, \& Zwagery, 2020) [1].

Peran masing-masing orang tua, baik ayah maupun ibu sangat berpengaruh kepada anak. Ayah berperan sebagai pemimpin yang dapat memberi perlindungan, rasa aman dan nyaman bagi anak, memenuhi kebutuhan ekonomi, mendisiplinkan, dan memberikan nilai moral dari kehidupan. Ibu berperan merawat, memahami, mengerti akan kebutuhan dan suasana hati anak serta mengabdikan hidupnya untuk keluarga terutama anak. Orang tua harus menerapkan pola asuh yang sesuai untuk menciptakan keluarga yang dinilai ideal dan harmonis.

Pengasuhan anak akan lebih baik bila ayah dan ibu menjalankan pengasuhan secara bersama (coparenting) yaitu apabila orangtua saling mendukung dan bekerja sama sebagai suatu tim, bukan bertentangan, ayah dan ibu sebaiknya diberikan porsi seimbang dalam hal pengasuhan dan tidak lagi menitikberatkan pada peran ibu saja. Peran sosok ayah dan keterlibatan ayah dalam mengasuh anaknya dapat masuk kedalam kesadaran anak melalui persepsi. (Huda, Safitri, \& Zwagery, 2020) [2].
Pikiran atau kemampuan berpikir, apalagi pola pikir, ditentukan raupan informasi. Seseorang yang tiada henti membelajarkan diri maka dapatan informasinya akan menentukan raupan atau kadar raupan informasi selanjutnya. (Abbas \& Erlyani, 2020) [3]. Orang tua harus mengambil sikap yang terbaik untuk anaknya.

Pada sisi lain, banyak juga orang tua yang pola asuhnya tidak berjalan dengan baik, terutama pada keluarga yang memiliki lebih dari satu anak. Terdapat perbedaan jenis kelamin dan karakter yang berbeda pada setiap anaknya dan terkadang salah seorang anak memiliki sikap yang tidak bersesuaian dengan orang tuanya serta timbul konflik yang beragam. Hal ini menyebabkan orang tua memiliki kecenderungan menyukai salah satu anak daripada yang lain.

Favoritisme orang tua adalah adanya perbedaan perlakuan yang diberikan oleh orang tua pada anak. Favoritisme orang tua terjadi ketika salah satu atau kedua orang tua menunjukkan sikap pilih kasih yang konsisten terhadap satu anak daripada yang lain. Hal ini akan memicu terjadinya pertentangan antar saudara kandung atau disebut juga sibling rivalry. Sibling rivalry merupakan kompetisi atau persaingan yang dilakukan antara saudara kandung untuk mendapatkan perhatian, cinta kasih, pengakuan maupun perlakuan yang sama dari kedua orang tuanya.

Terdapat berbagai macam reaksi sibling rivalry seperti munculnya perilaku agresif. Anak akan mencubit, memukul, menendang, mendorong, menangis yang meledak, manja, rewel, menangis tanpa sebab, dll. Sibling rivalry biasanya terjadi ketika anak memiliki rentang usia yang sama atau berdekatan dan memiliki jenis 
kelamin yang sama. Sibling rivalry yang tidak ditangani pada usia dini maka akan menyebabkan delayed effect, dimana pola perilaku akan tetap tersimpan pada bagian alam bawah sadar, pada usia 12 - 18 tahun dan dapat muncul kembali pada tahun selanjutnya dalam bentuk dan perilaku psikologikal yang merusak (Boyle, 2004) [4].

Anak yang mengalami sibling rivalry tidak mau membantu, tidak mau berbagi, tidak mau bermain atau mengasuh saudaranya, jika dipaksa akan menimbulkan sikap agresif terhadap saudaranya dan merusak. (Hurlock, 1989) [5].

Sibling rivalry yang disebabkan rasa cemburu biasanya berasal dari rasa takut dan dicampur marah karena adanya ancaman terhadap harga diri seseorang. Orang tua yang tidak dapat menangani persaingan antar saudara kandung ini maka akan terjadi berbagai dampak yang lebih serius.

\section{METODE}

Penulisan ini menggunakan metode kajian literatur dimana mengumpulkan data dengan mencari atau menggali data dari berbagai literatur seperti buku, jurnal ilmiah maupun sumber tulisan yang lain. Data-data yang telah didapatkan dari berbagai literatur dikumpulkan sebagai suatu kesatuan yang digunakan untuk mendapatkan landasan teori yang bisa mendukung pemecahan masalah yang sedang dikaji. Analisis data adalah upaya menyusun atau menata secara sistematis data yang telah terkumpul untuk meningkatkan pemahaman akan kasus atau permasalahan yang dikaji. Analisis data yang digunakan dalam penulisan ini adalah anotasi yang berarti kesimpulan sederhana dari suatu buku, jurnal, maupun sumber tulisan yang lain. Terdapat beberapa prosedur yang digunakan dalam penulisan ini. Pertama, mencari literatur yang relevan dengan permasalahan yang dibahas, mengorganisasi literatur yang akan ditinjau, menyatukan hasil organisasi literatur menjadi suatu ringkasan yang padu dengan mencari keterkaitan antar literatur.

Membaca, bukan hanya membaca buku atau yang tertulis saja. Membaca yang tertulis, yang tersurat, haruslah diimbuhi dengan yang tersirat. Tidak kalah penting, membaca alam, orang, masyarakat, tempat-tempat yang unik dan seterusnya. (Abbas, 2020) [6]. Dalam menggunakan metode ini kita tidak hanya membaca tapi perlu untuk menganalisis dan memahami permasalahannya.

\section{PEMBAHASAN}

Orang tua adalah faktor utama munculnya sibling rivalry dan berperan untuk mengatasi hal tersebut. Konflik dan pertengkaran antar orang tua dapat mengganggu pola kelekatan yang aman pada diri anak dan membuat anak kebingungan dengan dasar-dasar bagi hubungan yang sehat. (Saturrosidah, Mayangsari, \& Hidayatullah, 2020) [7].

Sibling rivalry adalah suatu persaingan diantara anak-anak dalam keluarga yang sama untuk memperoleh afeksi atau cinta kasih orang tua. ( Kartono, \& Gulo, 2000) [8]. Sibling rivalry adalah pertentangan saudara kandung baik adik dan kakak lakilaki, adik dan kakak perempuan, atau adik perempuan dan laki-laki, pertentangan antar saudara ini terjadi karena iri hati atau terdapat perbedaan minat bakat. (Chaplin, 2000) [9]. 
Sibling rivalry terjadi karena perbedaan reaksi dari orang-orang yang berada di sekelilingnya, termasuk ayah dan ibunya. Perasaan iri yang diwarnai dengan perselisihan yang akan mengakibatkan timbulnya sibling rivalry, selalu berjalan pada suatu alasan yaitu anak sedang melakukan pencarian tentang siapa diri mereka dan mereka merasa mendapatkan jumlah perhatian yang tidak adil dari orang tuanya. Walaupun orang tua telah memberikan perlakuan yang sama dan adil terhadap anaknya, namun anak seringkali berpikir bahwa perlakuan tersebut tetap tidak adil.

Ada beberapa hal yang memicu terjadinya pertentangan antar saudara adalah rasa cemburu yang mendalam, kebencian, rasa iri, dan perasaan ingin berkompetisi atau bersaing sehingga tidak mau kalah. Berbagai kecemburuan dapat diekspresikan dengan berbagai macam cara seperti aduan kepada ayah atau ibunya mengenai kesalahan yang telah diperbuat oleh kakak maupun adiknya. Hal yang paling membahayakan ketika anak sudah berani bertindak secara agresif seperti memukul, mencubit, mendorong maupun menendang kepada saudaranya.

Perilaku agresif adalah perilaku yang berniat untuk menyakiti orang lain, baik secara fisik maupun psikologis untuk mengekspresikan perasaan negatifnya sehingga dapat mencapai tujuan yang diinginkan. Tujuan utama dari perilaku agresif adalah luapan perasaan negatif seperti kecewa, tegang, marah, serta pada saat mengatasi suatu keinginan atau masalah yang mengganggu dalam memperoleh sesuatu. Perilaku agresif dilakukan dengan dua bentuk yaitu perilaku agresif berbentuk verbal maupun fisik. (Farah, Rachmah, \& Mayangsari, 2020) [10].

Sebagai manusia, kita memiliki kapasitas untuk merefleksikan pengalaman termasuk emosi. Emosi berubah seiring dengan perubahan dalam hubungan pribadilingkungan seperti yang dirasakan dan dievaluasi. Emosi negatif muncul ketika suatu peristiwa tidak sesuai dengan tujuan, fokus atau harapan positif seseorang. Salah satu bentuk dari emosi negatif adalah kekecewaan. Kekecewaan sering dikaitkan dengan kurangnya kontrol atas situasi. (Rahimi, Erlyani, \& Mayangsari, 2020) [11]. Anak biasanya belum bisa mengendalikan rasa emosi pada dirinya dan rasa kecewa memicu timbulnya sibling rivalry.

Penampilan fisik yang menarik merupakan sebuah potensi yang menguntungkan dan dapat dimanfaatkan untuk memperoleh hasil yang menyenangkan dalam suatu interaksi sosial. Penampilan fisik yang menarik biasanya memberikan kepuasan terhadap diri individu. Adanya citra tubuh memiliki pengaruh yang besar terhadap bagaimana individu menghadapi dirinya dan menjalani kehidupan sehari-hari. (Santoso, Fauzia, \& Rusli, 2020) [12]. Terkadang antar saudara perempuan sering muncul rasa minder akan penampilan fisik yang membuat rasa iri.

Anak yang mengalami sibling rivalry akan mengalami kerenggangan dengan saudaranya sehingga tidak mau saling bercerita, tidak mau saling membantu, tidak mau saling bermain serta mudah marah.

Sibling rivalry terjadi karena adanya persamaan jenis kelamin, memiliki rentang usia yang relatif sama, ia juga mengatakan 
faktor lain yang mempengaruhi adalah kepribadian anak, respon orang tua pada anak, nasehat yang diberikan orang tua pada anak ketika berkumpul bersama keluarga, ruang gerak dan kebebasan pada setiap anak. (Walker, 2010) [13].

Faktor yang mempengaruhi sibling rivalry yaitu sikap orang tua, biasanya anak pertama yang memiliki waktu lebih banyak bersama orang tua sehingga hubungan yang terbangun lebih erat dan anak cenderung bisa memenuhi apa yang orang tua inginkan daripada anak tengah maupun anak bungsu. Urutan posisi, dalam sebuah keluarga yang memiliki lebih dari satu anak, maka setiap anak memiliki tugasnya masing-masing dan peran yang sesuai dengan kodratnya. Seperti anak perempuan pertama harus membantu ibu dalam mengerjakan urusan rumah, tetapi anak perempuan ini menolak karena merasa adiknya juga bisa membantu. Jenis kelamin, anak laki-laki dan perempuan memiliki reaksi yang berbeda terhadap saudara kandungnya yang sesama jenis maupun berbeda jenis. Biasanya kakak perempuan sering mengatur adik lakilakinya. Perbedaan usia antar saudara kandung juga mempengaruhi cara bersikap satu sama lain dan cara orang tua memperlakukan mereka. Anak yang lebih tua biasa dipilih orang tua untuk dijadikan contoh bagi adik-adiknya. Anak yang lebih muda harus mengikuti dan mematuhi anak yang lebih tua. Jumlah saudara, jika dalam sebuah keluarga kecil maka akan meminimalisasi pertentangan atau persaingan antar saudara kandung. Hal ini disebabkan keluarga dengan jumlah saudara yang sedikit maka akan lebih banyak waktu berkumpul, berkomunikasi serta interaksi antar saudara yang berjalan baik. Sedangkan pada keluarga dengan jumlah saudara yang besar maka jarang adanya interaksi yang berkualitas antar saudara kandung. Jenis disiplin, terdapat tiga jenis disiplin yang sering diterapkan oleh orang tua yaitu permisif, demokratis dan otoriter. Keluarga dengan jenis disiplin otoriter, orang tua mengendalikan secara ketat hubungan antara saudara dan bersifat memaksa sehingga bukan keinginan anak, kebebasan berekspresi lebih dibatasi. Jika orang tua menerapkan jenis disiplin permisif maka anak akan melakukan segala hal dengan sesuka hatinya tanpa kontrol dari siapapun. Dengan demikian jenis disiplin yang paling bagus untuk diterapkan adalah disiplin demokratis dimana anak lebih disiplin dalam melakukan hal karena aturan-aturan dibuat bersama agar dapat belajar dan memahami antar anggota keluarga. Pengaruh orang luar, orang yang berada pada luar rumah atau lingkungan sekitarnya dapat mempengaruhi hubungan antar saudara, bisa akan kehadiran orang luar ke rumah, tekanan dari orang luar terhadap keluarga, dan perbandingan anak oleh orang luar rumah. Orang luar dapat memberikan suasana yang tidak kondusif dan membuat ketegangan di dalam rumah. (Hurlock, 1989) [14].

Interaksi teman sebaya mempunyai arti sangat penting karena mampu meningkatkan kemampuan anak dalam mengenali emosi orang lain, membangun hubungan dengan orang lain, membantu peranan sosial yang baru dan mengajarkan mobilitas sosial. (Kurniawan, Akbar, \& Rusli, 2020) [15]. Anak yang mengalami sibling rivalry akan timbul berkurangnya rasa percaya pada orang tua dan saudaranya. Jadi dengan adanya teman sebaya anak dapat bertukar cerita dan mungkin akan menemukan solusi atau cara 
agar membuat keadaan dirinya menjadi lebih baik.

Dalam hubungan persahabatan tidak hanya akan menimbulkan keakraban, tetpai juga menimbulkan ikatan emosional antar individu yang bersahabat yaitu dengan kelekatan. Gaya kelekatan mengacu pada sistem motivasi yang mendasari hubungan sosial yang menjelaskan bagaimana individu berhubungan dengan orang lain. (Putri, Anward, \& Zwagery, 2020) [16].

\section{KESIMPULAN}

Orang tua diharapkan dapat menerapkan pola asuh yang adil bagi anaknya. Pola asuh yang dipilih harus tepat dengan tahapan dan perkembangan anak.

Dukungan sosial dapat berarti sebagai kualitas dukungan yang dirasakan oleh seseorang, dimana seseorang percaya dan merasakan ada dukungan yang diberikan oleh keluarga, orang tua, saudara, dan lainnya. Dukungan sosial orang tua memberikan pengaruh yang cukup besar bagi anak karena menjadi solusi dan menumbuhkan harga diri yang positif. (Effendi, Akbar, \& Rachmah, 2020) [17].

Dukungan sosial sangat dibutuhkan pada saat seseorang sedang mengalami masalah, karena dukungan sosial dapat secara efektif mengurangi stres yang dialami oleh anak.

Diperlukan kekuatan individu untuk mampu bertahan menghadapi kesulitan atau yang disebut kecerdasan adversitas. Anak harus menumbuhkan kesadaran pada dirinya untuk selalu berpikir positif dan yakin bahwa bisa melalui berbagai masalah yang dihadapi karena segala hal yang terjadi juga ada esensinya sebagai proses perkembangan dan pendewasaan.
Optimisme juga membuat anak mempunyai energi baik dan memperkecil kemungkinan untuk mengalami gangguan fisik, depresi, menghadapi permasalahan. (Hariska, Akbar, \& Erlyani, 2020) [18].

\section{DAFTAR PUSTAKA}

[1] Ansyah, R., Safitri, J., \& Zwagery, R. V. (2020). HUBUNGAN PERSEPSI CO-PARENTING DENGAN INTERAKSI TEMAN SEBAYA PADA SISWA SEKOLAH MENENGAH PERTAMA NEGERI 2 MARTAPURA. Kognisia prodi Psikologi FK ULM, 2(1), 15-25.

[2] Huda, N., Safitri, J., \& Zwagery, R. V. (2020). HUBUNGAN ANTARA PERSEPSI KETERLIBATAN AYAH DALAM PENGASUHAN DENGAN KETERIKATAN PESERTA DIDIK KELAS IX PADA SEKOLAH DI SMPN 1 BANJARBARU. Kognisia prodi Psikologi FK ULM, 1(2), 119-123.

[3] Abbas, E. W., \& Erlyani, N. (2020). Menulis di Kala Badai Covid-19.

[4] Boyle, W. A. (2011). Sibling rivalry and why everyone should care about this age old problem.

[5] Hurlock, E. 1989. Perkembangan Anak Jilid 2. Jakarta:Erlangga.

[6] Abbas, E. W. (2020). Menulis Mudah, Menulis Ala Ersis Writing Theory.

[7] Saturrosidah, A., Mayangsari, M. D., \& Hidayatullah, M. S. (2020). PENGARUH KELEKATAN 
DENGAN

ORANGTUA

TERHADAP KECERDASAN

ADVERSITAS PADA REMAJA

KORBAN

PERCERAIAN. Kognisia prodi

Psikologi FK ULM, 1(2), 21-27.

[8] Kartono, K., \& Gulo, D. (1987). Kamus psikologi. Pionir Jaya.

[9] James, P. Chaplin. 2002. Kamus Lengkap Psikologi.

[10] Farah, V. T., Rachmah, D. N., \& Mayangsari, M. D. (2020). PENGARUH KESEPIAN TERHADAP PERILAKU AGRESIF PADA REMAJA LAKI-LAKI YANG TINGGAL DI PANTI ASUHAN X. Kognisia prodi Psikologi FK ULM, 1(2), 137-142.

[11] Rahimi, R. N., Erlyani, N., \& Mayangsari, M. D. (2020). EFEK INTERPERSONAL DARI EKSPRESI EMOSI KECEWA TERHADAP PERILAKU PROSOSIAL PADA SISWA SEKOLAH MENENGAH ATAS DI KECAMATAN

GAMBUT. Kognisia prodi Psikologi FK ULM, 2(2), 126-133.

[12] Santoso, M. V., Fauzia, R., \& Rusli, R. (2020). HUBUNGAN ANTARA KEPUASAN CITRA TUBUH DENGAN KECENDERUNGAN BODY DYSMORPHIC DISORDER PADA WANITA DEWASA AWAL DI KOTA BANJARBARU. Kognisia prodi Psikologi FK ULM, 2(1), 55-60.
[13] Walker, Kathy. 2010. Parenting a practical guide to raising preschool and primary-school children. Australia:Penguin Group.

[14] Hurlock, E. 1989. Perkembangan Anak Jilid 2. Jakarta:Erlangga.

[15] Kurniawan, D. R., Akbar, S. N., \& Rusli, R. (2020). HUBUNGAN INTERAKSI TEMAN SEBAYA DENGAN KEJENUHAN BELAJAR PADA SANTRI ALIYAH PONDOK PESANTREN AL FALAH PUTRA BANJARBARU. Kognisia prodi Psikologi FK ULM, 1(1), 48-54.

[16] Putri, L. A., Anward, H. H., \& Zwagery, R. V. (2020). PERBEDAAN KUALITAS PERSAHABATAN DITINJAU DARI GAYA KELEKATAN PADA MAHASISWA PSIKOLOGI FAKULTAS KEDOKTERAN ULM. Kognisia prodi Psikologi FK ULM, 1(1), 2328.

[17] Effendi, M. F., Akbar, S. N., \& Rachmah, D. N. (2020). HUBUNGAN ANTARA DUKUNGAN SOSIAL ORANG TUA DENGAN KESADARAN DIRI PADA SISWA SMPN 8 BANJARMASIN. Kognisia prodi Psikologi FK ULM, 2(1), 61-65.

[18] Hariska, C., Akbar, S. N., \& Erlyani, N. (2020). HUBUNGAN OPTIMISME DENGAN KECERDASAN ADVERSITAS PADA MASYARAKAT YANG TINGGAL DI DAERAH RAWA DESA PANDAHAN 
KECAMATAN BATI-

BATI. Jurnal Kognisia: Jurnal

Mahasiswa Psikologi Online, 3(1),

6-14. 